\title{
Timing of supplementation alters grazing behavior and milk production response in dairy cows
}

\author{
A. J. Sheahan, ${ }^{* 1}$ S. J. Gibbs, $†$ and J. R. Roche† \\ *DairyNZ, Private Bag 3221, 3240 Hamilton, New Zealand \\ †Faculty of Agriculture and Life Sciences, Lincoln University, PO Box 94, 7647 Lincoln, New Zealand
}

\begin{abstract}
Offering feed supplements to grazing dairy cows results in substitution of pasture; however, previous data indicate that the time at which concentrate supplements are offered might affect the level of substitution. These data indicated that cows grazed more intensely presunset, regardless of the amount of supplement offered. It was, therefore, hypothesized that substitution rate would be less, and response to supplement greater if cows received their supplement at the p.m. rather than the a.m. milking. Forty-eight multiparous, nonpregnant, Holstein-Friesian cows, approximately $60 \mathrm{~d}$ in milk, were randomly allocated to 1 of 3 treatments in an incomplete crossover arrangement. Treatments were pasture only, pasture $+3 \mathrm{~kg}$ of concentrate supplement dry matter (DM) offered during the a.m. milking (AMSUP), and pasture $+3 \mathrm{~kg}$ of concentrate supplement DM offered during the p.m. milking (PM-SUP). Time spent grazing and calculated pasture DM intake did not differ between the AM-SUP and PM-SUP cows. However, a tendency $(0.18 \mathrm{~kg}$ of milk $/ \mathrm{kg}$ of concentrate DM) was observed for an increased marginal milk response ( $\mathrm{kg}$ of milk $/ \mathrm{kg}$ of DM supplement) for the AM-SUP cows when compared with PM-SUP cows. Irrespective of when supplements were offered, supplementation reduced total grazing time by a similar amount, and the reduction in time spent grazing was evident throughout the day. Cows in the PM-SUP group ruminated for longer and cows in the AM-SUP group spent more time idle compared with the pasture only groups. Cows in the AM-SUP group grazed for less time during the major a.m. grazing bout following a.m. milking compared with PM-SUP cows; in comparison, the major p.m. grazing bout following p.m. milking was unaffected by supplementation. The results indicated
\end{abstract}

Received May 28, 2012.

Accepted September 18, 2012.

${ }^{1}$ Corresponding author: angela.sheahan@dairynz.co.nz possible improvements in marginal milk response to supplements from altering the timing of delivery.

Key words: timing of supplementation, grazing behavior, dairy cow

\section{INTRODUCTION}

Low DMI is a major limitation to milk production in pasture-based dairy systems resulting in nutrient intakes that are insufficient to match the milk production potential of the grazing dairy cow (Kolver and Muller, 1998). In an attempt to increase total DM and ME intakes, supplements may be offered to grazing cows. However, the marginal milk response (MR) to supplements varies markedly, primarily because of a reduction in pasture DMI (Stockdale, 2000; Bargo et al., 2003). The decrease in pasture DMI with increasing supplement DMI is termed substitution (Bargo et al., 2003).

Substitution is reflected by changes in the dairy cows grazing behavior, with a reported $12 \mathrm{~min}$ decrease in grazing time for every $1 \mathrm{~kg}$ of DM supplement consumed (Bargo et al., 2003; Sheahan et al., 2011) and an increase in rumination time (Sheahan et al., 2011). Sheahan et al. (2011) reported that when cows were supplemented at a.m. and p.m. milking, the effect on grazing time was not consistent throughout the day, with supplementation reducing grazing time during the day but not immediately preceding sunset, which is the most intensive grazing bout of the day (Gibb et al., 1998; Scaglia et al., 2009). Sheahan et al. (2011) hypothesized that the cessation of grazing following a.m. supplementation was due to neuroendocrine factors resulting from the digestion of feed, rather than physical factors, and that sunset signaled the end of grazing following p.m. milking, irrespective of supplementation in the p.m. Based on the lack of effect of concentrate supplementation on time spent grazing before sunset for cows supplemented in the a.m. and p.m., it was hypothesized that substitution would be less, and therefore, the milk production response to concentrate greater, when cows received the same amount of concentrate supplement in the p.m. rather than in the a.m. 


\section{MATERIALS AND METHODS}

This experiment was conducted at Lye Farm (DairyNZ, Hamilton, New Zealand) from September to October 2011, and was approved by the Ruakura Animal Ethics Committee, Hamilton, New Zealand.

\section{Experimental Design}

The experimental design was an incomplete crossover arrangement, with 48 multiparous, nonpregnant, Holstein-Friesian cows, approximately 60 DIM, randomly assigned to 1 of 3 treatments $(\mathrm{n}=16$ cows/treatment): pasture only (PAST), pasture $+3 \mathrm{~kg}$ of concentrate supplement DM offered during the a.m. milking (AMSUP), and pasture $+3 \mathrm{~kg}$ of concentrate supplement DM offered during the p.m. milking (PM-SUP). The initial concentrate supplement allocation was $1 \mathrm{~kg}$ of $\mathrm{DM} / \mathrm{d}$, and then increased by $1 \mathrm{~kg}$ of $\mathrm{DM} / \mathrm{d}$ until full allocation was obtained. Cows then underwent a $10-d$ adaptation period before a 7 -d measurement period. At the end of the 7-d measurement period, cows were reassigned to a new treatment in the following manner: of cows previously in the AM-SUP treatment group, 8 were assigned to PM-SUP and 8 to PAST treatment; of cows previously in the PM-SUP treatment group, 8 were assigned to AM-SUP treatment, and 8 to PAST treatment; of cows previously in the PAST treatment group, 8 were assigned to AM-SUP treatment and 8 to PM-SUP treatment. A 10-d adaptation period followed by a 7 -d measurement period was repeated.

\section{Pasture and Concentrate Supplement}

Cows were grazed as 1 herd for $24 \mathrm{~h} / \mathrm{d}$ for the duration of the experiment and were only removed for a.m. and p.m. milkings. Pasture allowance was sufficient to ensure DMI up to approximately $20 \mathrm{~kg}$ of $\mathrm{DM} / \mathrm{d}$ for the unsupplemented cows. Cows had access to a fresh allocation of pasture after each milking. Each allocation was $50 \%$ of the daily allowance. Pasture was of high quality (Table 1) throughout the experiment and each pasture allocation was sampled by hand plucking a representative pasture sample to simulate grazing, just before cows entering the paddock, for quality analysis (Dairy One Cooperative Inc., Ithaca, NY). The concentrate supplement was offered $(3 \mathrm{~kg}$ of $\mathrm{DM})$ during milking at either the a.m. or p.m. milking, in accordance with allocated treatment. The supplement was a pelleted concentrate composed of distillers grain $(35 \%$ DM), palm kernel expeller (25\% DM), maize grain ( $15 \%$ DM), wheat middlings ( $15 \% \mathrm{DM})$, and minerals $(10 \%$ DM). Refusals were recorded daily, with an average of $2.90 \mathrm{~kg}$ of DM and $2.96 \mathrm{~kg}$ of DM consumed $(P<0.05)$ for the AM-SUP and PM-SUP cows, respectively.

\section{Pasture DMI}

Pasture DMI was calculated from mean daily milk energy output plus cow maintenance requirements for BW change. Cows were weighed once per week after a.m. milking. Bodyweight gain/loss was calculated for each individual cow by calculating the difference in BW over the 4-wk period. The efficiency with which energy was used for milk production was assumed to be $65 \%$, and the maintenance requirements for lactating grazing dairy cows was $0.6 \mathrm{MJ} / \mathrm{kg}$ of $\mathrm{BW}^{0.75}$ (Holmes et al., 2003). The energy required for $1 \mathrm{~kg}$ of BW gain or supplied from $1 \mathrm{~kg}$ of BW loss was assumed to be 32 and $25 \mathrm{MJ} /$ cow per day, respectively (Holmes et al., 2003). Energy intake was divided by the mean pasture ME

Table 1. Chemical composition of bulked a.m. and p.m. pasture samples and concentrate supplement offered

\begin{tabular}{lccc}
\hline Item & a.m. Pasture $^{1}$ & p.m. Pasture $^{1}$ & Supplement $^{1}$ \\
\hline DM \% & 90.6 & 90.6 & 93.5 \\
Chemical composition (\% of DM) & & & \\
CP & 27.0 & 26.5 & 21.8 \\
ADF & 23.9 & 23.8 & 22.3 \\
NDF & 44.0 & 43.1 & 35.7 \\
Lignin & 2.4 & 2.4 & 5.2 \\
NFC & 22.8 & 24.3 & 34.5 \\
Starch & 0.6 & 0.6 & 14.3 \\
Fat & 4.3 & 4.2 & 5.65 \\
NSC & 14.8 & 18.4 & 26.4 \\
Ash & 9.9 & 9.8 & 10.5 \\
IVTD, ${ }^{4} 24$ h (\% of DM) & 90.8 & 90.8 & 75.5 \\
NDF, 24 h $\%$ of NDF) & 79.5 & 78.5 & 31.5 \\
ME $^{5}$ (MJ/kg of DM) & 13.9 & 13.9 & 10.3 \\
\hline
\end{tabular}

${ }^{1}$ Pasture samples were collected immediately before cows grazed fresh pasture allocation.

${ }^{4}$ IVTD $=$ in vitro true digestibility.

${ }^{5}$ Metabolizable energy was calculated from IVTD. 
concentration to calculate DMI and pasture DMI was calculated from total DMI minus concentrate intake:

DMI $(\mathrm{kg}$ of $\mathrm{DM} / \mathrm{d})=$

$\left(\frac{\text { Milk energy }+ \text { maintenance energy }+ \text { BW gain }(\text { or }- \text { BW loss })}{\text { Pasture }+ \text { concentrate ME }}\right)$.

\section{Milk Production}

Milking times were 0700 and 1600 h. Individual a.m. and p.m. milk yields were recorded daily (WestfaliaSurge Deutschland GmbH, Oelde, Germany) during the entire experiment, but only individual milk weights during the 7-d measurement periods were used for analyses. Separate a.m. and p.m. milk samples were collected on $2 \mathrm{~d}$ within both 7-d measurement periods for milk composition analysis. Milk fat, CP, casein, and lactose concentrations were determined by Fouriertransform infrared spectroscopy (FT120; Foss Electric A/S, Hillerød, Denmark) on separate p.m. and a.m. samples.

\section{Grazing Behavior}

Grazing behavior was recorded for $24 \mathrm{~h}$ during both 7 -d measurements periods. Time spent grazing, ruminating (lying and standing), and idle (not grazing or ruminating) was determined by recording each cow's activity at 10 -min intervals throughout a 24 -h period while cows were at pasture (Gary et al., 1970). Grazing for this experiment was defined as cows in the act of eating. The 24-h observations were further divided into 4 time blocks to determine the effect of treatment on cow grazing behavior at defined times during the day. The 4 time blocks were time block 1 (after a.m. milking to p.m. milking), time block 2 (after p.m. milking to sunset), time block 3 (after sunset to $2350 \mathrm{~h}$ ), and time block 4 (0000 h to a.m. milking). The duration of the major grazing bout after each milking was calculated as the difference between the time each cow entered the paddock and the time immediately before the recording of 2 consecutive nongrazing events (either ruminating or idle).

\section{Statistical Analysis}

Average a.m., p.m., and daily milk yields were calculated for each cow during each of the 2 measurement periods. Additionally, average fat, protein, casein, and lactose composition and yields were also calculated for each cow during the 2 measurement periods. The total time spent in a particular grazing behavior (grazing, ruminating, or idle) was calculated for each cow in each measurement period and during the defined time blocks and major grazing bout after a.m. and p.m. milking. Each of these calculated variables was then analyzed with GenStat 14.1 (VSN International Ltd., Hemel Hempstead, UK), using mixed models, including measurement period, treatment, and interaction of measurement period with treatment as fixed effects and cow and measurement period within cow as random effects. Equal variances were used for the 2 measurement periods.

\section{RESULTS}

The effects of a.m. or p.m. supplementation on milk production are presented in Table 2. Cows in the AMSUP and PM-SUP groups produced more $(P<0.001)$ milk and milk components $(\mathrm{kg} / \mathrm{cow}$ per day) than cows in the PAST group. A tendency $(P<0.07)$ existed for the AM-SUP cows to produce more milk $(\mathrm{kg} / \mathrm{cow}$ per day) than the PM-SUP cows. Cows in the AM-SUP group produced more $(P<0.001)$ milk and milk components at the a.m. milking than PAST and PM-SUP groups, which did not differ from each other. Similarly, cows in the PM-SUP produced more $(P<0.001)$ milk and milk components at p.m. milking than the PAST and AM-SUP groups, which did not differ from each other. Marginal MR to supplements for the AM-SUP and PM-SUP groups were 0.52 and $0.34 \mathrm{~kg}$ of milk $/ \mathrm{kg}$ of supplement DM, respectively. Supplementation resulted in a reduction in calculated pasture DMI (Table 2); PAST cows consumed more pasture than AM-SUP and PM-SUP groups, which did not differ from each other.

Summarized grazing behavior data are presented in Table 3. An effect was observed of treatment on the total time spent grazing: PAST cows grazed for 31 and 37 min longer $(P<0.01)$ than the AM-SUP and PMSUP cows, respectively; this reflected a reduction in time spent grazing of 11 and $13 \mathrm{~min} / \mathrm{kg}$ of supplement. No effect was observed of timing of supplementation on time spent grazing during the defined time blocks throughout the day, with the exception of time block 4 , when PM-SUP cows grazed for less $(P<0.05)$ time than the PAST cows. During the hours of darkness (time block 3 and 4$)$ PAST cows grazed for longer $(P<$ $0.05)$ than AM-SUP and PM-SUP cows (18 and 22 min longer, respectively). Cows in the AM-SUP group had a shorter $(P<0.05)$ major grazing bout following the a.m. milking than PM-SUP cows. In comparison, no effect was observed of treatment on the major grazing bout following the p.m. milking.

Timing of supplementation altered total time spent ruminating, with cows in the PM-SUP treatment ru- 
Table 2. Summary of milk production, milk components, and estimated pasture intake for cows on pasture only (PAST), pasture + a.m. supplement only (AM-SUP), and pasture + p.m. supplement only (PM-SUP)

\begin{tabular}{|c|c|c|c|c|c|}
\hline \multirow[b]{2}{*}{ Item } & \multicolumn{3}{|c|}{ Treatment } & \multirow[b]{2}{*}{$\mathrm{SED}^{1}$} & \multirow[b]{2}{*}{$P$-value } \\
\hline & PAST & AM-SUP & PM-SUP & & \\
\hline \multicolumn{6}{|l|}{ Daily } \\
\hline Pasture $\mathrm{DMI}^{2}(\mathrm{~kg} / \mathrm{d})$ & 16.8 & 15.1 & 14.9 & 0.151 & $<0.001$ \\
\hline Milk yield $(\mathrm{kg} / \mathrm{d})$ & 26.6 & 28.1 & 27.6 & 0.248 & $<0.001$ \\
\hline Fat $(\%)$ & 4.46 & 4.38 & 4.38 & 0.100 & 0.66 \\
\hline $\mathrm{CP}(\%)$ & 3.63 & 3.63 & 3.64 & 0.017 & 0.74 \\
\hline Casein $(\%)$ & 2.85 & 2.85 & 2.86 & 0.017 & 0.97 \\
\hline Lactose $(\%)$ & 4.76 & 4.77 & 4.74 & 0.019 & 0.27 \\
\hline Fat $(\mathrm{kg} / \mathrm{d})$ & 1.18 & 1.22 & 1.20 & 0.029 & 0.32 \\
\hline $\mathrm{CP}(\mathrm{kg} / \mathrm{d})$ & 0.96 & 1.01 & 1.00 & 0.010 & $<0.001$ \\
\hline Casein $(\mathrm{kg} / \mathrm{d})$ & 0.75 & 0.80 & 0.78 & 0.008 & $<0.001$ \\
\hline Lactose (kg/d) & 1.27 & 1.34 & 1.31 & 0.014 & $<0.001$ \\
\hline \multicolumn{6}{|l|}{ a.m. } \\
\hline Milk yield $(\mathrm{kg})$ & 17.4 & 18.9 & 17.2 & 0.291 & $<0.001$ \\
\hline Fat $(\%)$ & 3.87 & 4.06 & 3.41 & 0.166 & $<0.001$ \\
\hline $\mathrm{CP}(\%)$ & 3.60 & 3.59 & 3.62 & 0.018 & 0.25 \\
\hline Casein $(\%)$ & 2.81 & 2.80 & 2.81 & 0.019 & 0.84 \\
\hline Lactose $(\%)$ & 4.75 & 4.75 & 4.74 & 0.019 & 0.73 \\
\hline Fat $(\mathrm{kg})$ & 0.67 & 0.77 & 0.58 & 0.038 & $<0.001$ \\
\hline $\mathrm{CP}(\mathrm{kg})$ & 0.62 & 0.67 & 0.62 & 0.010 & $<0.001$ \\
\hline Casein $(\mathrm{kg})$ & 0.48 & 0.52 & 0.48 & 0.008 & $<0.001$ \\
\hline Lactose (kg) & 0.82 & 0.89 & 0.81 & 0.014 & $<0.001$ \\
\hline \multicolumn{6}{|l|}{ p.m. } \\
\hline Milk yield (kg) & 9.3 & 9.2 & 10.4 & 0.250 & $<0.001$ \\
\hline Fat $(\%)$ & 5.56 & 5.06 & 5.92 & 0.111 & $<0.001$ \\
\hline $\mathrm{CP}(\%)$ & 3.69 & 3.73 & 3.68 & 0.019 & $<0.05$ \\
\hline Casein $(\%)$ & 2.93 & 2.96 & 2.93 & 0.019 & 0.23 \\
\hline Lactose (\%) & 4.78 & 4.80 & 4.74 & 0.026 & 0.11 \\
\hline Fat $(\mathrm{kg})$ & 0.52 & 0.46 & 0.61 & 0.022 & $<0.001$ \\
\hline $\mathrm{CP}(\mathrm{kg})$ & 0.34 & 0.34 & 0.38 & 0.008 & $<0.001$ \\
\hline Casein (kg) & 0.27 & 0.27 & 0.30 & 0.007 & $<0.001$ \\
\hline Lactose (kg) & 0.44 & 0.44 & 0.49 & 0.012 & $<0.001$ \\
\hline
\end{tabular}

${ }^{1}$ Standard error of the difference.

${ }^{2}$ Pasture DMI was calculated from milk production.

minating for 24 and 28 min longer $(P<0.05)$ than PAST and AM-SUP groups, respectively; the greatest differences occurred during the hours of darkness (time blocks 3 and 4). No cows from any treatment were recorded ruminating in the period between p.m. milking and sunset (time block 2). An effect also existed of treatment on the total time spent idling with cows in the AM-SUP treatment: they were idle for 43 and 22 min longer $(P<0.01)$ than cows in the PAST and PMSUP treatments, respectively.

\section{DISCUSSION}

The objective of this experiment was to determine if previously reported differences in the effects of supplementation at a.m. and p.m. milking on grazing behavior (Sheahan et al., 2011) could be exploited to minimize pasture substitution and increase marginal MR to supplements. In the present experiment, total grazing time did not differ between AM-SUP and PMSUP cows. However, a tendency existed for an increased marginal MR when cows were supplemented in the a.m. rather than the p.m. The timing of supplementation did not affect calculated DMI, with results indicating a sustained decrease in grazing time, regardless of timing of supplementation.

Supplementing grazing cows in either the a.m. or the p.m. similarly reduced total time spent grazing compared with PAST cows. The decrease in time spent grazing (11-13 $\mathrm{min} / \mathrm{kg}$ of supplement DM) is consistent with the $12 \mathrm{~min} / \mathrm{kg}$ of supplement DM reported by Bargo et al. (2003) and Sheahan et al. (2011). However, the lack of effect on total time spent grazing when supplementing in the p.m. rather than the a.m. is contrary to the proposed hypothesis. This result was unexpected particularly because the grazing behavior was consistent with the concept that neither a.m. nor p.m. supplementation affected grazing time between p.m. supplementation and sunset, but a.m. supplementation reduced time spent grazing in the major a.m. grazing bout. Consistent with Sheahan et al. (2011), grazing during the period between p.m. milking and 
Table 3. Summary of grazing, ruminating, and idling behavior ${ }^{1}$

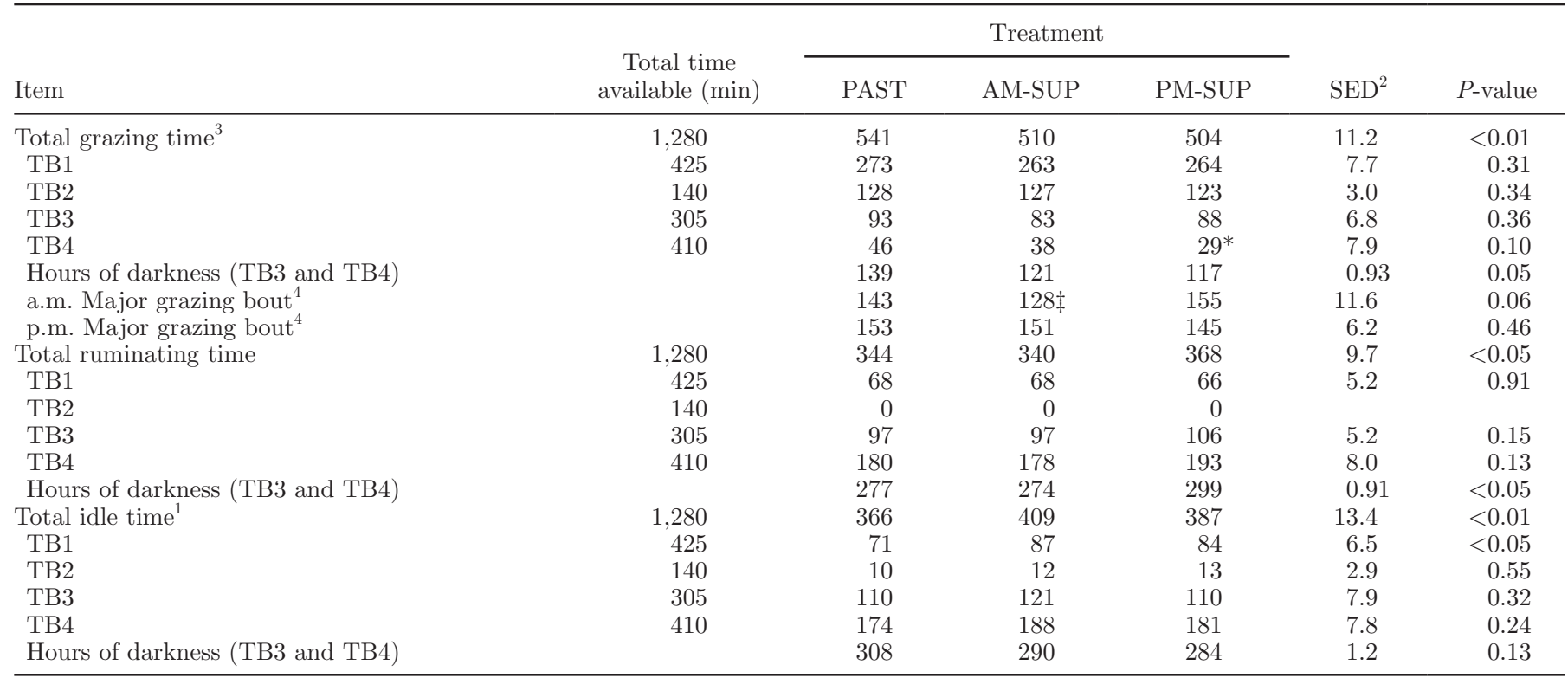

${ }^{1}$ Daily total grazing, ruminating, and idling times; time spent grazing, ruminating, and idling during 4 time blocks (TB) during a 24-h period; and length of major grazing bout following a.m. and p.m. milking for cows on pasture only (PAST), pasture + a.m. supplement only (AM-SUP), and pasture + p.m. supplement only (PM-SUP).

${ }^{2}$ Standard error of the difference.

${ }^{3}$ Total time spent grazing, ruminating, or idle does not include time cows were off pasture for milking. TB1: after a.m. milking to p.m. milking; TB2: after p.m. milking to sunset; TB3: after sunset to 2350 h; TB4: 0000 h to a.m. milking.

${ }^{4}$ Duration of major grazing bout after a.m. and p.m. milking (min) was calculated as the difference between the time cows entered the paddock and the time immediately before the recoding of 2 consecutive nongrazing events.

${ }^{*} P<0.05$ : difference between PM-SUP and PAST groups; $\ddagger P<0.05$ : difference between AM-SUP and PM-SUP groups.

sunset does not appear to be regulated by products of digestion or associated endocrine factors but rather appears to be regulated by impending darkness. Despite the lack of effect on total time spent grazing, data from the present experiment provide some evidence of the effects of supplementation on factors regulating DMI in grazing cows, as the difference in total grazing time was a result of an equal reduction in time spent grazing in 3 of the 4 defined periods within a 24 -h period. These data are consistent with those of Sheahan et al. (2011), who supplemented cows at a.m. and p.m., and indicate that the effect of supplementation on grazing time is sustained well beyond the act of ingestion and, likely, beyond the period of digestion.

Between a.m. and p.m. milking, grazing times were not affected by timing of supplementation; however, the length of the first a.m. grazing bout, which is one of the major grazing bouts during the day (Gibb et al., 1998; Taweel et al., 2004), was reduced in the AMSUP cows, despite less time grazing during the hours of darkness than unsupplemented cows. This result is consistent with Roche et al. (2007) and Sheahan et al. (2011), who reported that the cessation of the major grazing bout in the a.m. is regulated by neuroendocrine factors associated with products of digestion. As rumen $\mathrm{pH}$ and VFA were not measured in the current experiment, it is not possible to determine likely associations between products of digestion and factors circulating in the blood. However, offering the concentrate supplement likely altered the ruminal acetate:propionate ratio, increasing propionate production at the expense of acetate compared with unsupplemented cows (Orskov, 1986; Bannink et al., 2008). Therefore, the reduced major a.m. grazing bout in the AM-SUP cows is consistent with supplementation increasing propionate production, a factor known to increase insulin production and reduce grazing time (Oba and Allen, 2003). The lack of effect due to supplementation on the p.m. major grazing bout indicates a photoperiod effect on intake regulation that may supersede digestion-derived neuroendocrine factors (Sheahan et al., 2011). Data, therefore, indicate different factors regulating hunger and satiety in diurnal animals.

The increased rumination time for the PM-SUP cows is consistent with reports that supplementing grazing cows increased time spent ruminating (Phillips and Leaver, 1986; Sheahan et al., 2011). However, the rumination time for the AM-SUP cows was similar to that 
of PAST cows, indicating that the factors regulating rumination are dependent on timing of feed. As the majority of rumination occurred during the hours of darkness, when little grazing occurred, the reduced rumination time indicates that the AM-SUP did not need to further masticate their feed and, therefore, could spend more time in idle behavior.

Increased milk production, when grazing cows are supplemented with concentrated feeds, is widely recognized (Bargo et al., 2002; Kennedy et al., 2008; Sheahan et al., 2011). Results from the current study indicated a tendency for increased marginal MR when supplements were offered in the a.m. rather than p.m. This is contrary to Trevaskis et al. (2004), who reported an increase in milk production when supplementing grazing dairy cows in the p.m. compared with the a.m. This could be due to the allocation of daily pasture allowance once per day in their study, compared with fresh pasture allocations after a.m. and p.m. milkings in the current study.

As total grazing time did not differ between supplemented treatments, the increase in milk production may be related to bite mass or bite rate rather than grazing time. Numerous studies have reported that increasing the amount of concentrate reduces grazing time but does not affect bite rate or bite mass; (see review by Bargo et al., 2003); however, bite mass data are often calculated indirectly and this, therefore, does not take into account grazing dynamics within a grazing bout. Short-term intake rate is dependent upon bite mass (Gibb, 2006), which decreases as rumen fill increases, even though bite rate is maintained (Chilibroste et al., 1997; Gregorini et al., 2007). Bite mass for the PM-SUP cows may have been reduced after p.m. supplementation, despite similar grazing times, due to the presence of extra feed in the rumen compared with PAST and AM-SUP cows. If true, cows supplemented in the p.m. would, therefore, have reduced their bite mass, at a time of the day when grazing is most intensive (Gibb et al., 1998; Taweel et al., 2004), and also when the NSC concentration in the pasture is increased compared with the a.m. (Orr et al., 2001). Increased milk production has been reported when cows are fed pasture with greater NSC concentration (Miller et al., 2001) or when offered their fresh allocation of pasture in the afternoon (Orr et al., 2001). These data suggest an effect of subtle changes in pasture composition on bite mass or outputs of rumen fermentation. Future work investigating the timing of supplementation will require more detailed grazing behavior and rumen fermentation measurements, as results of the present study indicate that grazing time alone does not sufficiently explain treatment effects on milk production.

\section{CONCLUSIONS}

Supplementing grazing dairy cows at either a.m. or p.m. milking altered grazing behavior compared with cows eating pasture alone. Data indicate a sustained reduction in grazing time throughout the day, irrespective of the time that supplements were offered. Although grazing time and calculated pasture DMI were similar in supplemented cows, a tendency was observed for an increased marginal MR when cows were supplemented in the a.m. rather than the p.m. Further work investigating the products of digestion and their effect on physiological hunger and satiety factors, and how these affect grazing behavior and milk production is warranted to understand the complexities of DMI regulation in grazing cows.

\section{ACKNOWLEDGMENTS}

The authors acknowledge assistance and contributions from the DairyNZ Lye Farm (Hamilton, New Zealand) staff, the DairyNZ technical team, and Barbara Dow (Dairy NZ) for statistical analysis. The authors are very grateful to J. Kay and K. Mandok (both at Dairy NZ) for critical evaluation of the manuscript. This work was funded by New Zealand dairy farmers through DairyNZ Inc.

\section{REFERENCES}

Bannink, A., J. France, S. Lopez, W. J. J. Gerrits, E. Kebreab, S. Tamminga, and J. Dijkstra. 2008. Modelling the implications of feeding strategy on rumen fermentation and functioning of the rumen wall. Anim. Feed Sci. Technol. 143:3-26.

Bargo, F., L. D. Muller, J. E. Delahoy, and T. W. Cassidy. 2002. Performance of high producing dairy cows with three different feeding systems combining pasture and total mixed rations. J. Dairy Sci. 85:2948-2963.

Bargo, F., L. D. Muller, E. S. Kolver, and J. E. Delahoy. 2003. Invited review: Production and digestion of supplemented dairy cows on pasture. J. Dairy Sci. 86:1-42.

Chilibroste, P., S. Tamminga, and H. Boer. 1997. Effects of length of grazing session, rumen fill and starvation time before grazing on dry-matter intake, ingestive behaviour and dry-matter rumen pool sizes of grazing lactating dairy cows. Grass Forage Sci. 52:249257.

Gary, L. A., G. W. Sherritt, and E. B. Hale. 1970. Behavior of Charolais cattle on pasture. J. Anim. Sci. 30:203-206.

Gibb, M. J. 2006. Grassland management with emphasis on grazing behaviour. Pages 141-157 in Fresh Herbage for Dairy Cattle. A. Elgersma, J. Dijkstra, and S. Tamminga, ed. Springer, Dordrecht, the Netherlands.

Gibb, M. J., C. A. Huckle, and R. Nuthall. 1998. Effect of time of day on grazing behaviour by lactating dairy cows. Grass Forage Sci. 53:41-46.

Gregorini, P., S. A. Gunter, C. A. Masino, and P. A. Beck. 2007. Effects of ruminal fill on short-term herbage intake rate and grazing dynamics of beef heifers. Grass Forage Sci. 62:346-354.

Holmes, C. W., I. M. Brookes, D. J. Garrick, D. D. S. Mackenzie, T. J. Parkinson, and G. F. Wilson. 2003. Milk Production from Pasture. Massey University, Palmerston North, New Zealand. 
Kennedy, E., M. O'Donovan, L. Delaby, and F. P. O'Mara. 2008. Effect of herbage allowance and concentrate supplementation on dry matter, milk production and energy balance of early lactating dairy cows. Livest. Sci. 117:275-286.

Kolver, E. S., and L. D. Muller. 1998. Performance and nutrient intake of high producing Holstein cows consuming pasture or a total mixed ration. J. Dairy Sci. 81:1403-1411.

Miller, L. A., J. M. Moorby, D. R. Davies, M. O. Humphreys, N. D. Scollan, J. C. MacRae, and M. K. Theodorou. 2001. Increased concentration of water-soluble carbohydrate in perennial ryegrass (Lolium perenne L.): Milk production from late-lactation dairy cows. Grass Forage Sci. 56:383-394.

Oba, M., and M. S. Allen. 2003. Dose-response effects of intraruminal infusion of propionate on feeding behavior of lactating cows in early or mid-lactation. J. Dairy Sci. 86:2922-2931.

Orr, R. J., S. M. Rutter, P. D. Penning, and A. J. Rook. 2001. Matching grass supply to grazing patterns for dairy cows. Grass Forage Sci. 56:352-361.

Orskov, E. R. 1986. Starch digestion and utilization in ruminants. J. Anim. Sci. 63:1624-1633.

Phillips, C. J. C., and J. D. Leaver. 1986. The effect of forage supplementation on the behaviour of grazing dairy cows. Appl. Anim. Behav. Sci. 16:233-247.
Roche, J. R., A. J. Sheahan, L. M. Chagas, and D. P. Berry. 2007. Concentrate supplementation reduces postprandial plasma ghrelin in grazing dairy cows: A possible neuroendocrine basis for reduced pasture intake in supplemented cows. J. Dairy Sci. 90:1354-1363.

Scaglia, G., H. T. Boland, and W. E. Wyatt. 2009. Effects of time of supplementation on beef stocker calves grazing ryegrass. II. Grazing behavior and dry matter intake. Prof. Anim. Sci. 25:749-756.

Sheahan, A. J., E. S. Kolver, and J. R. Roche. 2011. Genetic strain and diet effects on grazing behavior, pasture intake, and milk production. J. Dairy Sci. 94:3583-3591.

Stockdale, C. R. 2000. Levels of pasture substitution when concentrates are fed to grazing dairy cows in Northern Victoria. Aust. J. Exp. Agric. 40:913-921.

Taweel, H. Z., B. M. Tas, J. Dijkstra, and S. Tamminga. 2004. Intake regulation and grazing behavior of dairy cows under continuous stocking. J. Dairy Sci. 87:3417-3427.

Trevaskis, L. M., W. J. Fulkerson, and K. S. Nandra. 2004. Effect of time of feeding carbohydrate supplements and pasture on production of dairy cows. Livest. Prod. Sci. 85:275-285. 